\title{
Enterococcus faecium L-3 in Eradication of Helicobacter pylori: In-vivo and In-vitro
}

Natalia Baryshnikova ${ }^{1 *}$, Elene Ermolenko ${ }^{2,3}$, Alena Svarval ${ }^{4}$, Raya Ferman ${ }^{4}$, Alexander Colobov ${ }^{5}$, Galina Alechina $^{2}$, Natalia Roshina ${ }^{4}$, Yury Uspenskiy ${ }^{1}$, Thomas Haertlé ${ }^{6}$ and Alexander Suvorov ${ }^{2,3}$

${ }^{1}$ Pavlov First St-Petersburg State Medical University, ul. Lva Tolstogo, 6-8, Sankt-Peterburg, 197022, Russia

${ }^{2}$ Institute of Experimental Medicine, St-Petersburg, Russia

${ }^{3}$ St-Petersburg State University, University Embankment, 7/9, Sankt-Peterburg, 199034, Russia

${ }^{4}$ Pasteur Institute, St-Petersburg, Russia

${ }^{5}$ Institute of Pure Biochemicals, St-Petersburg, Russia

${ }^{6}$ INRA, Nantes, France

\section{Abstract \\ Usage of probiotics as component of anti-helicobacter therapy had been recently approved as a promising trend in the clinical practice. Over the years, we observed high efficacy of probiotic multi bacteriocinogenic strain Enterococcus faecium L-3 as an additional component of the standard triple therapy in eradication of Helicobacter pylori (H.p.) in patients with chronic gastritis associated with H. pylori infection. The cultivation of H.p. in the presence of live probiotic cultures of E. faecium L-3, Escherichia coli M17, Lactobacillus plantarum 8R-A3 showed superior antagonistic activity of enterococci relatively to other tested bacteria. The anti-helicobacter activity of chemically synthesized enterococcal bacteriocins EntB and Enx $\beta$ were studied using 6 strains of $H$. pylori. The strain-specific action of synthetic enterocins used was determined. Testing of sensitivity of $H$. pylori. to probiotics and their metabolites in vitro would be important for the selection and prediction of the clinical effectiveness of probiotics as well as development of new anti-helicobacter drugs and lines of combined therapies based on enterocins.}

\section{Publication History:}

Received: June 05, 2017

Accepted: October 07, 2017

Published: October 09, 2017

\section{Keywords:}

Anti-helicobacter activity, Bacteriocins, Enterococcus faecium L3,

\section{Background}

In recent years, a significant decline in eradication efficiency with standard triple therapy for Helicobacter pylori (H.p.) infection was observed. These levels are not acceptable anymore. Various centers are working on new methodologies to enhance therapeutic outcomes, including probiotic application. According to Maastricht-V: "Only certain probiotics have been shown to be effective in reducing GI side effects caused by $H$. $p$. eradication therapies. Specific strains should be chosen only upon the basis of a demonstrated clinical efficacy" [1]. Moreover, some H. p. infected patients have an allergic reaction to antibiotics or refuse to take antibiotics. In these cases, probiotics can be an effective alternative method of therapy. Probiotics also can provide some other effects, for example, the positive influence of on the human immune, digestive, endocrine systems or the ability for direct inhibition of $H$. pylori by bacteriocins. Previously, several scientists saw the positive effect of various strains belonging to Lactobacillus spp., Bifidobacterium spp., Saccharomyces boulardii, Bacillus subtilis on eradication H.p. during standard triple therapy [2-9]. The anti-helicobacter activity of live probiotic lactobacilli and bifidobacteria was also demonstrated in vitro. Recently the activity of seven bacteriocins of lactic acid bacteria (nisin A; lacticins A164, $\mathrm{BH} 5$, JW3, and NK24; pediocin PO2; and leucocin K) was evaluated against the three strains of $H$. p. [10]. It was shown, that the degree of antimicrobial activity of the bacteriocins varied depending on the indicator strain used.

Only in last decade, several reports on the use of probiotic enterococci in the treatment of diseases of an infectious and noninfectious nature were published. It was shown, that E. faecium L-3 could inhibit the growth of many pathogenic gram-positive and gram-negative bacteria [11-15]. The high anti-helicobacter activity of the probiotic "Laminolact», which contains E. faecium L-3, was revealed. For example, it was shown, that adding of E. faecium L-3 to the standard eradication therapy improved its efficacy on $15 \%$ [7].
Monotherapy with «Laminolact» could eradicate H. p. in $48 \%$ of patients with chronic gastritis [16]. That is why we decided to use $E$. faecium L-3 in our studies in vivo and in vitro.

There is evidence that some probiotic enterococci are more effective than the other probiotics belonging to different species but these effects were not always equally effective $[8,16]$. This may be associated with the condition of the host organism, sensitivity of the pathogen to the action of the probiotic and its metabolites, primarily bacteriocins. We can assume that the high antimicrobial activity of the strain of enterococci could be related to their bacteriocinogenicity. However, the unequal efficiency of probiotic might be associated with the individual sensitivity of strains of H.p. to live enterococci or their products with antimicrobial activity. Unfortunately, in the current State of the Art efficacy of probiotic in the eradication of helicobacter infection and influence of enterocins on the growth of different strains of H.p. is poorly understood.

\section{Aim}

The purpose of the study evaluate the clinical efficacy of different probiotics in patients with chronic gastritis associated with H.p. infection and anti-helicobacter activity of probiotic enterococci and their bacteriocins in vitro.

"Corresponding Author: Dr. Natalia Baryshnikova, Pavlov First St-Petersburg State Medical University, ul. Lva Tolstogo, 6-8, Sankt-Peterburg, 197022, Russia, Tel: +7-921-301-33-77; E-mail: baryshnikova_nv@mail.ru

Citation: Baryshnikova N, Ermolenko E, Svarval A, Ferman R, Colobov A, et al. (2017) Enterococcus faecium L-3 in Eradication of Helicobacter pylori: In-vivo and In-vitro. Int J Clin Med Microbiol 2: 123. doi: https://doi.org/10.15344/24564028/2017/123

Copyright: @ 2017 Baryshnikova et al. This is an open-access article distributed under the terms of the Creative Commons Attribution License, which permits unrestricted use, distribution, and reproduction in any medium, provided the original author and source are credited. 
Citation: Baryshnikova N, Ermolenko E, Svarval A, Ferman R, Colobov A, et al. (2017) Enterococcus faecium L-3 in Eradication of Helicobacter pylori: In-vivo and In-vitro. Int J Clin Med Microbiol 2: 123. doi: https://doi.org/10.15344/2456-4028/2017/123

Page 2 of 4

\begin{abstract}
Materials \& Methods
E. faecium L-3 was originally isolated from milk product, patented in Russian Federation (№ 2220199), and deposited in Belgian Coordinated Collection of Miroorganisms (BCCM) № BBBM/LMG/ BP1/F415B, 15.12.2012. Complete genome sequence of strain $E$. faecium L-3 was obtained, using 454 pyrosequencing on the GS FLX platform and deposited into GenBank №SUB168082. The genome size is $2,6 \mathrm{Mb}$ and contains 2717 genes. This strain genome contains the genes encoding for enterocins $\mathrm{A}, \mathrm{B}, \mathrm{X} \alpha \mathrm{X} \beta$ [14]. E. faecium L-3 is included in different health-food products: «Laminolact», «Bakfir» and «BioBio» and have a long history of usage as probiotics in Russia. E. faecium L-3 was used more than 25 years for the therapy and prevention of gastrointestinal, allergic and autoimmune diseases affiliated with dysbiosis and infection pathology [17].
\end{abstract}

Strain of Lactobacillus plantarum 8R-A3 was isolated from probiotic «Lactobacterin». Previously we demonstrated that this probiotic strain carries genomic locus, presumably responsible for the synthesis of the two bacteriocins - plantaricin EF and NC8 [18]

Strain E.coli M17 /p Colap [Patent 2144954, C12N1/21, A61K35/74 27.01.2000 Russia], deposited in PMBC № 7448 was isolated from probiotic «Bificol» (Russia). The genome of this strain contains a plasmid, carrying a gene encoding for Colicin E1.

\section{Chemically synthesized enterocins}

The peptides: enterocin $\mathrm{B}(\mathrm{Ent} \mathrm{B})$ and enterocin $(\operatorname{EntX} \beta)$ with a molecular weight of $5,47 \mathrm{kDa}$ and $4,0 \mathrm{kDa}$, were synthesized in situ by the solid-phase method with an «Applied Biosystems 430A» automatic synthesizer using $\mathrm{Na}$-Boc protected amino acid derivatives. The crude synthetic peptides were purified on semi-preparative HPLC column.

\section{Experiments in vitro}

Study 1: 14 strains of H. p. (clinical isolates from the collection of bacterial cultures of the Pasteur Institute were successfully isolated from dyspeptic patients and cultivated). Cultivation of bacteria was carried out employing standard conditions for $H$. pylori $[19,20]$ Columbian agar was used as the basis of the nutrient medium for the isolation and cultivation of $H$. $p$. Each sample biopsy was seeded simultaneously into two Petri dishes with agar. Incubation was performed in microaerophilic conditions (oxygen content of about 5\%). After that, "Laminolact» an official medicine with E. faecium strain L-3 $[17,21]$, was dissolved in distilled water $1: 100$, and added on agar with different strains of H.p. We analyzed the growth of H.p. after incubation for 7 days by the following criteria: absence of growth, low growth, the presence of growth. In case of the absence of growth, the strain was considered as sensitive to the probiotic.

Study 2: five strains of $H$. $p$. isolated from patients from the present study (added to the collection of bacterial cultures of the Pasteur Institute), were used. Incubation was made in standard conditions for H. pylori E. faecium strain L-3, E.coli M17, Lactobacillus plantarum 8R-A3 (isolated from probiotics «Bificol» and «Lactobacterin», corresponently) were added in different concentrations (1-6 CFU/ $\mathrm{ml}$ ) into the bottom layer of agar. Different $H$. p. cultures were applied (in the concentration of $8 \mathrm{lg} \mathrm{CFU} / \mathrm{ml}$ ) on the surface of the top layer of agar. The assessment of growth of $H$. $p$. was analyzed after 7 days of incubation. Antagonistic activity was analyzed after determination of the minimal inhibitory quantity (MIQ) of live probiotic bacteria, as it was described previously [22].

Study 3: The anti-helicobacter activity of chemically synthesized (Applied Biosystems 430-A, USA) enterococcal bacteriocins: EntB and $\operatorname{Entx} \beta$ were evaluated using the six strains of H.p. which were isolated during the clinical study (added to the collection of bacterial cultures of the Pasteur Institute). The drops of antimicrobial peptides (in different concentrations) were added to the surface of the bacterial lawn. Zones of growth inhibition were detected after incubation of H.p. in anaerobic condition for 5 days. The anti-helicobacter activity was evaluated using minimal inhibitory concentration (MIC) of enterocins $(\mathrm{mcg} / \mathrm{ml})$ inhibited the growth of H.p.

\section{Clinical observation}

56 patients with dyspepsia were observed in gastroenterology department of Saint-Petersburg city hospital. After medical examination, 37 patients were diagnosed with chronic gastritis associated with H.p. infection. These patients were included in the study: analysis of efficacy and safety of administration of $E$. faecium L-3 as an anti-helicobacter medicine. Local Ethical Committee of the Institute of Experimental Medicine approved study. All the patients signed the informed consent for participation in this study.

According to administrated therapy, all patients were divided into two groups. Patients from group 1(17 patients) received probiotic (which contained E. faecium strain L-3 7,5 lg CFU/g 3 times a day during one month.

Patients from the group 2 (20 patients) received standard eradication therapy: omeprazole $20 \mathrm{mg}$ twice a day during 7 days, amoxicillin $1000 \mathrm{mg}$ twice a day during 7 days, clarithromycin 500 mg twice a day during 7 days.

Complains estimation (for analysis of therapy efficacy and possible adverse events), stomach endoscopy with biopsies from the stomach antrum for $H$. p. detection (rapid urease test, histological method, polymerase chain reaction) were made for all patients before and in 1.5-2 months after treatment. Negative results obtained by all three methods used were considered as successful eradication of $H$. $p$. Efficacy of $H$. p. eradication was estimated by intention to treat criteria.

Statistical analysis was performed in Excel for Windows.

\section{Results and Discussion}

\section{Eradication of H.p. in vivo}

Regress of gastric complaints (epigastric pain, heartburn, nausea) was in both groups of patients but in group 2 we saw a tendency to diarrhea. It can be the result of usage of antibiotic without probiotics. Efficacy of eradication with probiotic was not much worse than standard triple therapy. It is important to note that triple therapy (group 2) of $H$. pylori did not provide sufficient efficacy (was lower than $80 \%$ ) (figure 1).

Analysis of the group of patients taking "Laminolact», containing E. faecium strain L-3, had a promising result of eradication of $H$. p.. Application of probiotic enterococci employed as a monotherapy provided the efficacy of probiotic treatment of $H$. p.. in $39 \%$ of cases. These results were significantly higher than the level of spontaneous 
Citation: Baryshnikova N, Ermolenko E, Svarval A, Ferman R, Colobov A, et al. (2017) Enterococcus faecium L-3 in Eradication of Helicobacter pylori: In-vivo and In-vitro. Int J Clin Med Microbiol 2: 123. doi: https://doi.org/10.15344/2456-4028/2017/123

Page 3 of 4

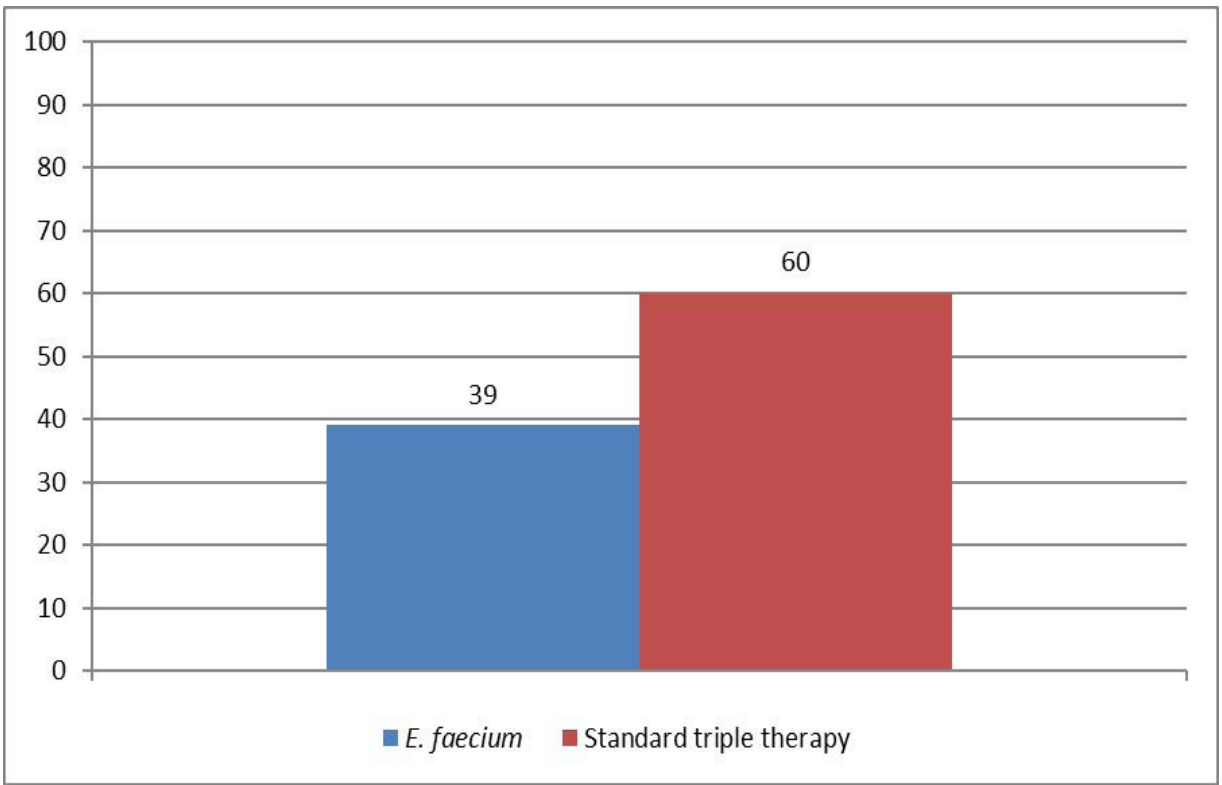

Figure 1: Efficacy of H. pylori eradication in different study groups.

Axis X: type of therapy

Axis Y: \% of efficacy eradication

Helicobacter eradication (approximately 5\%) We are explaining this improvement as a combination of positive influence of probiotic on the human immune system and by the direct inhibition of Helicobacter by bacteriocins of probiotic strain. Clinical and laboratory data suggested that probiotic E. faecium strain L-3 can be recommended as an alternative for the patients suffering from the side effects of the standard eradication therapy for example related to antibiotics. Application of probiotic led to the more successful eradication.

\section{Probiotic bacteria antagonistic activity and strain-specific sensitivity of $H . p$. in vitro}

Previous studies investigated the common activity of probiotics especially lactobacilli by estimation of speed of reaction, growth dynamic, bacteriostatic and bacteriocidic effects of probiotics and antibiotics $[11,12]$. Only a few number of publications have information about the investigation of supernatants and bacteriocins of lactic-acid bacteria [10]. The action of enterococci in this respect was not studied yet.

In the first part of in vitro experiments, our group observed the inhibition of $H$. p. growth was revealed in $78.6 \%$ of cases with $E$. faecium strain L-3.

Second part of the study was desinged to evaluate the antagonistic activity of three probiotic bacteriocinogenic strains E. faecium L-3, Lactobacillus plantarum 8R-A3 and Escherichia coli M17. Minimal inhibitory quantity (MIQ) of probiotic Escherichia, Lactobacilli, and Enterococci was estimated for five strains of $H$. p. (figure 2). The most effective strain among the probiotics used was of E. faecium. Minimal quantity of Lactobacilli, Enterococci, and Escherichia inhibiting the growth of H.p. were 2,6 lg CFU/ml, 1,4 CFU/ml and 2,9 CFU/ml, respectively.

The anti-helicobacter activity of two synthetic enterococcal bacteriocins - EntB and $\operatorname{Entx} \beta$ was tested against six strains of H.p., isolated from patients with gastritis.

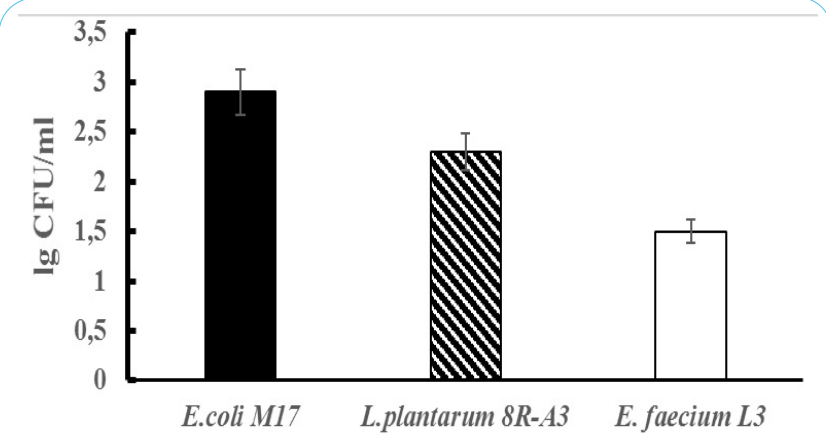

Figure 2: The anti-helicobacter activity of live probiotic cultures (double-layer agar method)

Axis X: type of microorganism

Axis Y: anti-helicobacter activity activity

We used the simplest conventional method for evaluation of the antibacterial activity of bacteriocins. For this purpose, chemically synthesized antimicrobial peptides, applied to the surface of agar with newly sown culture, formed the zones of growth inhibition, which are quite visible on the bacterial lawn formed after incubation for 7 days (Figure 3).

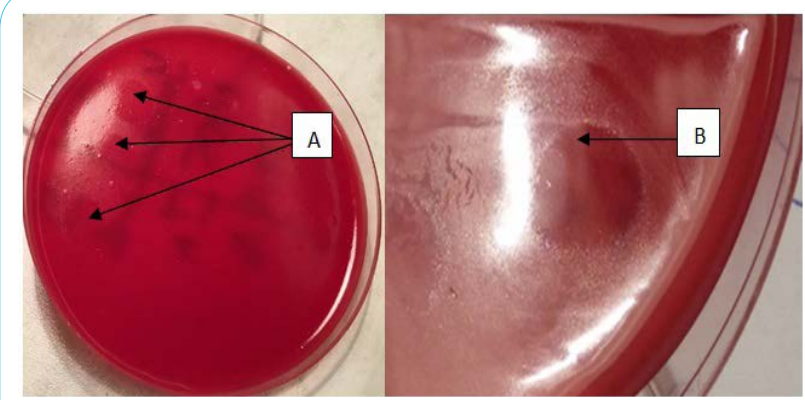

Figure 3: Areas of $H$. pylori growth inhibition with bacteriocins EntB and Entx $\beta$ in vitro (A and B - areas of absence of growth). 
Citation: Baryshnikova N, Ermolenko E, Svarval A, Ferman R, Colobov A, et al. (2017) Enterococcus faecium L-3 in Eradication of Helicobacter pylori: In-vivo and In-vitro. Int J Clin Med Microbiol 2: 123. doi: https://doi.org/10.15344/2456-4028/2017/123

Page 4 of 4

Both enterocins at a concentration of $1 \mu \mathrm{g} / \mathrm{ml}$ or less did not act on any strain of H.p. For two strains, the MIC of these antimicrobial peptides could not be determined because it was above $100 \mu \mathrm{g} / \mathrm{ml}$. The MIC of EntB was $10 \mu \mathrm{g} / \mathrm{ml}$ identical for the four strains. The antagonistic activity of EntXb was somewhat less than EntB. The MIC of Entx $\beta$ for the two strains was $10 \mu \mathrm{g} / \mathrm{ml}$, for one $-100 \mu \mathrm{g} / \mathrm{ml}$. (Table $1)$.

\begin{tabular}{|l|l|l|l|l|l|l|}
\hline $\begin{array}{l}\text { Enterocins/ } \\
\text { № strain }\end{array}$ & 101 & 105 & 112 & 157 & 100 & 80 \\
\hline EntB & $>100$ & 10 & 10 & 10 & $>100$ & 10 \\
\hline Entx $\beta$ & $>100$ & 10 & 100 & 10 & $>100$ & 10 \\
\hline
\end{tabular}

Table 1: Minimal inhibitory concentration of enterocins $(\mathrm{mcg} / \mathrm{ml})$ against different strains of Helicobacter pylori.

It is important to note that in this work the clinical efficacy and anti-helicobacter activity of the same enterococci strains and its metabolites were studied first both in vitro and in vivo. In the previous studies, only different strains of lactobacilli were used [4].

\section{Conclusions}

Results of the study demonstrate the differences in the activity of three bacteriocinogenic probiotic strains belonging to different species against H.p. E. faecium L-3 was found as the most effective probiotic in this study. This effect can be caused by the production of enterocins. The data obtained support the usage of enterococcal probiotics for the correction of dysbiosis and treatment of infectious diseases including H.p. related gastritis and ulcers. In our opinion, in vitro results can be associated with direct inhibition of $H$. $p$. by the probiotics. Eradication therapy with probiotics was more effective than the standard triple therapy without probiotics. Different efficacy of treatment can be associated with the sensitivity of different strains of H.p., host-microorganisms relationship and antagonistic activity of the probiotic. It is known that antibacterial features of $E$. faecium L-3 against streptococci, staphylococci, listeria, enterobacteria and non-fermentative gram-negative bacteria bacteria were prominent and had a strain-specific character $[13,15,16]$. The antagonistic activity chemically synthesized enterocin B against E.coli ML-35p was revealed by us in advance by in vitro study [15]. The anti-helicobacter activity of $E$. faecium could be associated with bacteriocins due to the fact that chemically synthesised enterocins encoded by the strain genome provided the individual antibacterial activity. The results demonstrate the strain-specific sensitivity of H.p. to enterocines and the presence H.p. strains, which exhibited multi-resistance to enterocines. The detection of sensitivity helicobacteria to enterocins could be useful for the individual choice of probiotic during the H.p. infection treatment and for the development of drugs based on the most effective bacteriocins or the selection of probiotic strains, which produce more effective anti-helicobacter peptides. However, future studies are needed to confirm our results.

\section{Competing Interests}

The authors declares that they have no competing interests.

\section{Funding}

The study was supported by Russian scientific foundation grant 1615-10085 and international grant with INRA France 14.616.21.0024.

\section{References}

1. Malfertheiner P, Megraud F, O'Morain CA, Gisbert JP, Kuipers EJ, et al. (2017) Management of Helicobacter pylori infection-the Maastricht V/ Florence Consensus Report. Gut 66: 6-30.

2. Coconnier MH, Liévin V, Hemery E, Servin AL (1998) Antagonistic activity against Helicobacter infection in vitro and in vivo by the human Lactobacillus acidophilus strain LB. Appl Environ Microbiol 64: 4573-4580.

3. O'Connor HJ (1994) Eradication of Helicobacter pylori. European journal of gastroenterology \& hepatology 6: S113-S119.

4. Lesbros-Pantoflickova D, Corthésy-Theulaz I, Blum AL (2007) Helicobacter pylori and probiotics. The Journal of nutrition 137: $812 \mathrm{~S}-818 \mathrm{~S}$.

5. Gotteland M, Brunser O, Cruchet S (2006) Systematic review: are probiotics useful in controlling gastric colonization by Helicobacter pylori? Aliment Pharmacol Ther 23: 1077-1086.

6. Szajewska H, Horvath A, Piwowarczyk A (2010) Meta-analysis: the effects of Saccharomyces boulardii supplementation on Helicobacter pylori eradication rates and side effects during treatment. Aliment Pharmacol Ther 32: 1069-1079.

7. Baryshnikova NV (2011) Helicobacter pylori infection and colon dysbiosis Lambert LAP Lambert Academic Publishing, pp 50-130.

8. Rustamov M, Baryshnikova N, Rustamova L (2016) Helicobacter 21 Suppl 1: 149.

9. Baryshnikova NV (2012) Helicobacter pylori-associated gastroenterological diseases: genetic features and probiotic treatment. Beneficial Microbes 3 : 157-161.

10. Kim TS, Hur JW, Yu MA, Cheigh Cl, Kim KN, et al. (2003) Antagonism of Helicobacter pylori by bacteriocins of lactic acid bacteria. J Food Prot 66: 3-12.

11. Ermolenko El, Chernysh AI, Martsinkovskaia IV, Suvorov AN (2006) Influence of probiotic enterococci on the growth of Streptococcus agalactiae. Zh Mikrobiol Epidemiol Immunobiol 5: 73-77.

12. Ermolenko El (2009) Bacteriocins of enterococci, problems and perspectives of using. Vestn of Saint-Petrsburg university 11: 78-93.

13. Yermolenko E, Kolobov A, Chernysh A, Suvorov A (2011) Influence of synthetic peptide inductors on antibacterial activity of enterococci. Beneficial Microbes 2: 9-13.

14. Karaseva A, Tsapieva A, Pachebat J, Suvorov A (2016) Draft genome sequence of probiotic Enterococcus faecium strain L-3. Genome announcements. Genome Announc 4: e01622-15.

15. Ermolenko E (2011) Lactic acid bacteria Labert academic Publishing, Deutchland Labert, Deutchland: 283

16. Suvorov AN, Simanenkov VI, Zakharova NV, Baryshnikova NV (2013) Efficacy of Enterococcus faecium L3 in therapy of Helicobacter pylor infection. International Scientific conference on bacteriocins and antimicrobial peptides, 28

17. Suvorov A (2013) Gut microbiota, probiotics, and human health. Biosci Microbiota Food Health 32: 81-91.

18. Tsapieva A, Duplik N, Suvorov A (2011) Structure of plantaricin locus of Lactobacillus plantarum 8P- A3. Benef Microbes 2: 255-261.

19. Zhebrun AB, Svarval' AV, Balabash OA, Ferman RS (2013) Helicobacter pylori population characteristic in patients with diseases of gastrointestinal tract. Zh Mikrobiol Epidemiol Immunobiol 2: 90-96.

20. Sainsus N, Cattori V, Lepadatu C, Hofmann-Lehmann R (2008) Liquid culture medium for the rapid cultivation of Helicobacter pylori from biopsy specimens. Eur J Clin Microbiol Infect Dis 27: 1209-1217.

21. Suvorov A, Simanenkov V, Gromova L, Kolodjieva V, Tsapieva A, et al (2011) Enterococci as probiotics or autoprobiotics. Prebiotics and probiotics potential for human health, Ivanova I (ed), Paisi Hilendarski, Sofia, 104-112.

22. Ermolenko El, Isakov VA, Zhdan-Pushkina S, Tets VV (2003) Quantitative characterization of antagonistic activity of lactobacilli. Zhurnal mikrobiologii, epidemiologii, i immunobiologii 5: 94-98. 